\title{
Concentrations and pharmacokinetic parameters of MRI and SPECT hepatobiliary agents in rat liver compartments
}

\author{
Catherine M. Pastor ${ }^{1,2^{*}}$ (D), Florian Joly ${ }^{1}$, Valérie Vilgrain ${ }^{1,3}$ and Philippe Millet ${ }^{4,5}$
}

\begin{abstract}
Background: In hepatobiliary imaging, systems detect the total amount of agents originating from extracellular space, bile canaliculi, and hepatocytes. They add in situ concentration of each compartment corrected by its respective volume ratio to provide liver concentrations. In vivo contribution of each compartment to liver concentration is inaccessible. Our aim was to quantify the compartmental distribution of two hepatobiliary agents in an ex vivo model and determine how their liver extraction ratios and cholestasis (livers lacking canalicular transporters) might modify it.

Methods: We perfused labelled gadobenate dimeglumine (Bopta, $200 \mu \mathrm{M}, 7 \%$ liver extraction ratio) and mebrofenin (Meb, $64 \mu \mathrm{M}, 94 \%$ liver extraction ratio) in normal $(n=18)$ and cholestatic $(n=6)$ rat livers. We quantified liver concentrations with a gamma counter placed over livers. Concentrations in hepatocytes and bile canaliculi were calculated. Mann-Whitney and Kruskal-Wallis tests were used.

Results: Hepatocyte concentrations were 2,043 $\pm 333 \mu \mathrm{M}$ (Meb) versus $360 \pm 69 \mu \mathrm{M}$ (Bopta, $p<0.001$ ). Meb extracellular concentrations did not contribute to liver concentrations (1.3 $\pm 0.3 \%)$. The contribution of Bopta extracellular concentration was $12.4 \pm 1.9 \%$ ( $p<0.001$ versus Meb). Contribution of canaliculi was similar for both agents (16\%). Cholestatic livers had no Bopta in canaliculi but their hepatocyte concentrations increased in comparison to normal livers.
\end{abstract}

Conclusion: Hepatocyte concentrations are correlated to liver extraction ratios of hepatobiliary agents. When Bopta is not present in canaliculi of cholestatic livers, hepatocyte concentrations increase in comparison to normal livers. This new understanding extends the interpretation of clinical liver images.

Keywords: Membrane transport proteins, Cholestasis, Hepatocytes, Bile canaliculi, Extracellular space

\footnotetext{
* Correspondence: catherine.pastor@unige.ch

${ }^{1}$ Centre de recherche sur l'inflammation, Inserm, U1149, CNRS, ERL8252,

Université de Paris, F-75006 Paris, France

${ }^{2}$ Department of Radiology, University Hospital of Geneva, Rue

Gabrielle-Perret-Gentil, 4, 1205 Geneva, Switzerland

Full list of author information is available at the end of the article
}

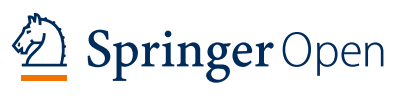

(c) The Author(s). 2021 Open Access This article is licensed under a Creative Commons Attribution 4.0 International License, which permits use, sharing, adaptation, distribution and reproduction in any medium or format, as long as you give appropriate credit to the original author(s) and the source, provide a link to the Creative Commons licence, and indicate if changes were made. The images or other third party material in this article are included in the article's Creative Commons licence, unless indicated otherwise in a credit line to the material. If material is not included in the article's Creative Commons licence and your intended use is not permitted by statutory regulation or exceeds the permitted use, you will need to obtain permission directly from the copyright holder. To view a copy of this licence, visit http://creativecommons.org/licenses/by/4.0/. 


\section{Key points}

- The ex vivo model quantifies the compartmental distribution of gadobenate dimeglumine and mebrofenin.

- Hepatocyte concentrations are correlated to the liver extraction ratio of hepatobiliary agents.

- Contribution of bile canaliculi to liver concentrations is similar for gadobenate dimeglumine and mebrofenin (16\%).

- Cholestatic livers had low gadobenate dimeglumine concentrations in canaliculi but hepatocyte concentrations increased in comparison to normal livers.

\section{Background}

The quantification of liver function in cirrhotic patients is important to evaluate the tolerance to partial hepatectomy and estimate prognosis. Besides various plasma biomarkers, imaging with hepatobiliary agents is another option to quantify liver volume and function [1-4]. The function is quantified by imaging parameters such as the maximum liver enhancement or activity, the time to obtain the maximal signal, and the elimination half-life of agents from livers [5-7].

Several hepatobiliary agents such as gadobenate dimeglumine (Bopta), gadoxetic acid, and mebrofenin (Meb) are transported inside hepatocytes across the sinusoidal Organic anion transporting polypeptide (Oatp). To efflux from hepatocytes, agents cross the Multidrug resistance associated protein 2 (Mrp2) located on the canalicular membrane and Mrp3 on the sinusoidal membrane. Hepatocyte concentrations reflect the balance between these uptake and excretory transporter activities. When Oatp disappears in advanced hepatocellular carcinoma, the tumour appears hypointense on hepatobiliary phase in comparison to surrounding hepatocytes that retain sinusoidal transporters [8-10]. Besides hepatocytes, imaging also relies on concentrations inside the extracellular compartment and bile canaliculi. However, this compartmental distribution (or contribution of each compartment to liver concentrations) is inaccessible in vivo.

Hepatobiliary imaging detects the total amount of agents originating from the extracellular space, bile canaliculi, and hepatocytes. The system adds the in situ concentrations of each compartment corrected by its respective volume ratio to liver to provide liver concentrations [11]. Thus, in cirrhotic livers, parenchymal hypointensity on hepatobiliary phase reflects the increased volume ratio of the extracellular space when fibrosis replaces hepatocytes. The hepatocyte volume decreases and in situ hepatocyte concentrations are impaired by the low expression of Oatp [12, 13]. Volume ratio of bile canaliculi to liver and in situ concentrations are unknown in cirrhosis.

The isolated and perfused rat liver is an ex vivo model of pharmacokinetic research which can quantify the compartmental distribution of transporter-dependent hepatobiliary imaging [14]. Hepatobiliary agent concentrations are measured in hepatic veins and common bile duct. By placing a gamma counter over livers, it is possible to mimic an imaging system and quantify liver concentrations during the perfusion of Bopta or Meb. A preperfusion of gadopentetate dimeglumine (Dtpa) quantifies the extracellular concentrations, whilst concentrations in bile canaliculi are calculated from bile concentrations and the volume ratio of canaliculi to liver [15].

The aim of our study was to quantify the compartmental distribution of two hepatobiliary agents in an ex vivo model and determine how their liver extraction ratios and cholestasis (livers lacking canalicular transporters) might modify it. From the accumulation and decay profiles of hepatocyte concentrations, new pharmacokinetic parameters will be described to better understand hepatobiliary images.

\section{Methods}

Isolated and perfused rat livers

A total of 24 livers were evaluated. Livers from 18 normal male Sprague-Dawley rats were isolated and perfused under anaesthesia (Pentobarbital, $50 \mathrm{mg} \mathrm{kg}^{-1}$, i.p.). The protocol was carried out in accordance with the Swiss Guidelines. It was accepted by the institutional ethical Committee (University of Geneva) and approved at the veterinary office in Geneva (No. 1006/3384). We also perfused Bopta in six cholestatic rats lacking Mrp2 [16].

The abdominal cavity was opened, and the portal vein was cannulated [17]. The abdominal vena cava was transected and an oxygenated Krebs-Henseleit-bicarbonate (KHB) solution was pumped into the portal vein, the solution being discarded by a vena cava transection. The liver flow rate $\left(Q_{\mathrm{H}}\right)$ was slowly increased up to $30 \mathrm{~mL} / \mathrm{min}$. A cannula was inserted in the right atrium and the abdominal inferior vena cava ligated, allowing solutions perfused through the portal vein to efflux by hepatic veins.

Livers were perfused with KHB solution \pm imaging agents using a nonrecirculating system: livers were perfused with fresh solutions and solutions flowing from hepatic veins were discarded (Fig. 1c). The common bile duct was cannulated to collect bile samples and measure bile concentration $\left(C_{\text {bile }}, \mu \mathrm{M}\right)$ and bile flow rate ( $Q_{\text {bile, }} \mu \mathrm{L} / \mathrm{min} /$ liver) every $5 \mathrm{~min}$. Agent concentrations in hepatic veins $\left(C_{\text {out }}, \mu \mathrm{M}\right)$ were collected every $5 \mathrm{~min}$.

We diluted agents in the $\mathrm{KHB}$ solution that contain $118 \mathrm{mM} \mathrm{NaCl}, 1.2 \mathrm{mM} \mathrm{MgSO}_{4}, 1.2 \mathrm{mM} \mathrm{KH_{2 }} \mathrm{PO}_{4}, 4.7$ $\mathrm{mM} \mathrm{KCl}, 26 \mathrm{mM} \mathrm{NaHCO}$, and $2.5 \mathrm{mM} \mathrm{CaCl}_{2}$. The solution was equilibrated with a mixture of $95 \% \mathrm{O}_{2}-5 \%$ 


\section{a. Perfusion of imaging agents}

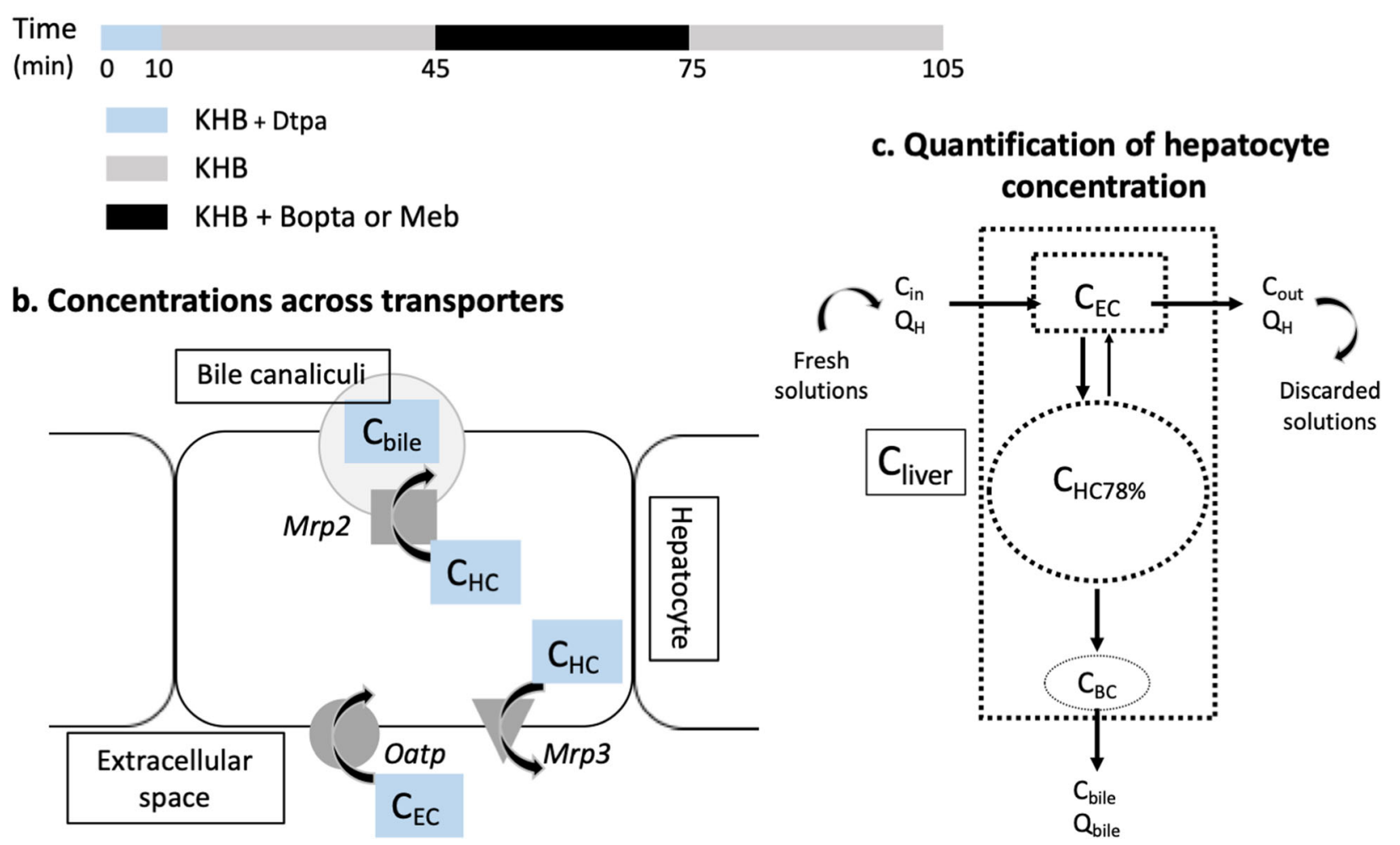

Fig. 1 a Perfusion of imaging agents. Livers $(n=15)$ were successively perfused with Krebs-Henseleit bicarbonate solution $(K H B)+200 \mu M{ }^{153} G d-$ Dtpa, KHB, KHB + $200 \mu \mathrm{M}^{153} \mathrm{Gd}$-Bopta, and KHB. Nine additional livers were perfused with KHB $+64 \mu \mathrm{M}^{99 \mathrm{~m}} \mathrm{Tc}-\mathrm{Dtpa}$, KHB, KHB +64 $\mu \mathrm{M}^{99 \mathrm{~m}} \mathrm{Tc}-\mathrm{Meb}$, and KHB. Illustration of Bopta and Meb transport across Oatp, Mrp2, and Mrp3 (b) and quantification of hepatocyte concentration (c). Extracellular concentration $\left(C_{\mathrm{E}}\right)$ is quantified during Dtpa perfusion. $C_{\mathrm{HC} 78 \%}$ for hepatocyte concentration measured by the counter. In situ concentration in bile canaliculi is similar to concentration in common bile duct $\left(C_{\text {bile }}\right)$. Bile canaliculi concentration measured by the counter $\left(C_{B C}\right)$ is $C_{\text {bile }} \cdot 0.0043$ (volume ratio of canaliculi to liver). $C_{H C 78 \%}$ is defined by $C_{\text {liver }}-C_{E C}-C_{B C}$. Liver flow rate $\left(Q_{H}\right)$, bile excretion rate $\left(Q_{\text {bile }}\right)$, concentration in portal vein $\left(C_{\text {in }}\right)$, and concentration in hepatic veins $\left(C_{\text {out }}\right)$

$\mathrm{CO}_{2}$. The electrolytic composition and $\mathrm{pH}$ were normal. We did not add proteins in the solution and agent entry into livers was not modified by protein binding within sinusoids. Unknown protein binding in extracellular space, hepatocytes, and bile canaliculi might modify Bopta and Meb pharmacokinetics. However, Bopta and Meb have a low protein binding that should not interfere with transfer rates across compartments $[18,19]$.

\section{Perfusion of imaging agents (Fig. 1a)}

Fifteen livers (nine normal and six cholestatic livers lacking Mrp2) were perfused with gadopentetate dimeglumine (Dtpa; Magnevist ${ }^{\circ}$; Bayer imaging) to measure the liver extracellular concentrations because the agent distributes only into this compartment. After a rinse period to eliminate Dtpa from livers (within $5 \mathrm{~min}$ ), livers were perfused with the hepatobiliary agent gadobenate dimeglumine (Bopta, MultiHance; Bracco Imaging). Bopta distributes in the extracellular space, hepatocytes, and bile canaliculi. Both agents were labelled with ${ }^{153} \mathrm{Gd}$ by adding ${ }^{153} \mathrm{GdCl}_{3}(1 \mathrm{MBq} / \mathrm{mL})$ to commercially available $(0.5 \mathrm{M})$ solutions used for patients. ${ }^{153} \mathrm{Gd}-\mathrm{Dtpa}$ and ${ }^{153} \mathrm{Gd}$-Bopta were diluted to a $200-\mu \mathrm{M}$ concentration. Bopta perfusion was followed by a rinse period with KHB solution.

Nine normal livers were perfused with Technescan Dtpa $^{\circ}$ (Dtpa, b.e.imaging $\mathrm{GmbH}$ ) and mebrofenin (Meb; Choletec $^{\circ}$; Bracco Imaging). Dtpa and Meb (25 mg) were labelled with the same radiotracer ${ }^{99 \mathrm{~m}} \mathrm{Tc}$ (7 and $11 \mathrm{MBq}$, respectively). Both solutions are commercially available for patients. Dtpa distributes only in the extracellular compartment whilst Meb distributes in the extracellular space, hepatocytes, and bile canaliculi. Both agents were diluted to a $64-\mu M$ concentration. Dtpa and Meb perfusion were followed by a rinse period with KHB solution. The protocol period lasted $105 \mathrm{~min}$.

To quantify agent concentrations in liver compartments, a gamma counter that collects count rates every $20 \mathrm{~s}$ was placed $1 \mathrm{~cm}$ above a right liver lobe. At the end of experiment, Bopta or Meb liver amounts were 
measured by an activimetre and related to the last count rates. Bopta or Meb concentrations in the common bile duct and hepatic veins were measured with a gamma counter. Concentrations in large vessels, bile ducts, and livers are expressed in $\mu \mathrm{M}$ units. We considered that $1 \mathrm{~g}$ of liver was close to $1 \mathrm{~mL}$.

\section{Calculation of hepatocyte concentrations (Fig. 1c)}

The gamma counter delineated a region of interest from which Bopta or Meb amounts originating from the extracellular, bile canaliculi, and hepatocyte compartments were divided by the rat liver weight to obtain liver concentrations $\left(C_{\text {liver }}, \mu \mathrm{M}\right)$. Concentrations in the extracellular compartment $\left(C_{\mathrm{EC}}, \mu \mathrm{M}\right)$ were constant during the perfusion of Dtpa. The concentrations detected by the counter were similar to the in situ $C_{\mathrm{EC}}$ because the distribution volume is 1 . We assumed that concentrations inside the bile canaliculi were similar to those measured in the common bile duct $\left(C_{\text {bile, }}, \mu \mathrm{M}\right)$. The concentrations of bile canaliculi detected by the counter $\left(C_{\mathrm{BC}}\right)$ were $C_{\mathrm{bile}} \cdot 0.0043$ according to Blouin et al. [20] who measured the volume ratio of bile canaliculi to liver in rat biopsies. The hepatocyte concentrations $\left(C_{\mathrm{HC} 78 \%}\right)$ detected by the counter were equal to $C_{\text {liver }}-C_{\mathrm{EC}}-C_{\mathrm{BC}}$ and originate from $78 \%$ of the liver volume according to Blouin et al. [20]. To convert $C_{\mathrm{HC} 78 \%}$ measured by the counter into in situ concentration into hepatocytes $\left(C_{\mathrm{HC100 \%}}\right)$, we applied the equation: $C_{\mathrm{HC100 \%}}=(100 / 78)$ $\times C_{\mathrm{HC} 78 \%}$.

\section{Profiles of liver concentrations over time}

To analyse Bopta or Meb liver accumulation over time, we searched for nonlinear regressions that fit the data using the GraphPad Prism software (version 8, GraphPad Software, La Jolla CA, USA). In normal livers, data fitted either a continuous hinge function (segmental regression lines with gentle connexion) [21] or a segmental linear regression with abrupt connexion [22]. Both regressions were described by two lines $L_{1}$ and $L_{2}$ intersecting at $T_{0}(\mathrm{~min})$ or time when bile excretion starts to impact the accumulation. Before $T_{0}$, the slope of $L_{1}$ (slo${ }_{\mathrm{pe}} L_{1, \text { liver }}$ in $\mu \mathrm{M} / \mathrm{min}$ ) characterises Bopta or Meb uptake into hepatocytes across Oatp. After $T_{0}$, the slope of $L_{2}$

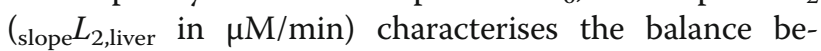
tween entry and efflux transporter activities.

During the rinse period, no agent enters into liver and concentration decay fitted a one-phase decay $Y=\left(Y_{0}-\right.$ plateau) $\cdot e^{-k e l \cdot \mathrm{X}}+$ plateau. The software provided a decay (elimination) rate constant $\left(k_{\text {el, liver }}\right.$ in $\left.\min ^{-1}\right)$ and a

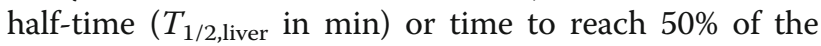
initial concentrations. With the assumption that the hepatocyte volume $\left(V_{\mathrm{HC}}, \mathrm{mL}\right)$ was $78 \%$ of liver weight, the elimination clearance from hepatocytes $\left(\mathrm{CL}_{\mathrm{el}, \mathrm{HC}}\right.$ in $\mathrm{mL} / \mathrm{min}$ ) was calculated by $\mathrm{CL}_{\mathrm{el}, \mathrm{HC}}=k_{\mathrm{el}, \mathrm{HC}} \times V_{\mathrm{HC}}$.
Liver concentrations were acquired every $20 \mathrm{~s}$ by the counter but this acquisition frequency is difficult to implement in clinical imaging. Therefore, we simulated decreased acquisition frequencies $(2,5$, and $10 \mathrm{~min})$ and determined the lower frequency that gives $T_{0}$, slope $L_{1, \text { liver }}$, slope $L_{2, \text { liver }}$, and $k_{\text {el,liver }}$ similar to those obtained at a 20 -s acquisition frequency.

\section{Profiles of hepatocyte concentrations over time}

Liver pharmacokinetic parameters do not fully characterise the transporter functions of hepatocytes because liver concentrations also include extracellular and canaliculi concentrations. Consequently, we measured all parameters using hepatocyte concentrations and compared them to those obtained in livers.

\section{Statistical analysis}

Data are given as means \pm SD. To compare Bopta or Meb parameters and to determine the influence of Mrp2 absence on Bopta parameters, we used a Mann-Whitney test (GraphPad Prism version 8, GraphPad Software, San Diego, USA). To compare the effect of acquisition frequencies on pharmacokinetic parameters, we used a Kruskal-Wallis test with multiple comparisons between frequencies. Difference between groups was considered significant for $p<0.05$.

\section{Results \\ Compartmental distribution of Bopta and Meb concentrations}

Figure 2 and Table 1 describe how liver extraction ratios and cholestasis interfere with the compartmental distribution of hepatobiliary agents. Meb has a $94 \%$ liver extraction ratio and provided much higher maximal $C_{\mathrm{HC} 78 \%}$ $(2,043 \pm 333 \mu \mathrm{M})$ than Bopta $(360 \pm 69 \mu \mathrm{M}, p<0.0001)$ which has a $7 \%$ liver extraction ratio. Consequently, Meb $C_{\text {out }}$ in hepatic veins was low, whilst Bopta $C_{\text {out }}$ was only slightly lower than the perfused concentrations (Table 1). Meb concentrations in the extracellular space did not contribute much to liver concentrations (Table 1, $1.3 \pm 1.9 \%$ ). The maximal Meb concentrations detected by the counter in bile canaliculi $\left(C_{\mathrm{BC}}\right)$ were $393 \pm 61 \mu \mathrm{M}$ and accounted for $17 \pm 4 \%$ of liver concentrations. In contrast, maximal Bopta $C_{\mathrm{EC}}(60 \pm 10 \mu \mathrm{M})$ participated to liver concentrations all along the accumulation period $(12.4 \pm 1.9 \%, p<$ 0.001 versus Meb). Maximal Bopta $C_{\mathrm{BC}}$ was $66 \pm 11 \mu \mathrm{M}$ and accounted for $14 \pm 4 \%$ (no difference with Meb, $p=$ 0.09). The lack of Mrp2 in cholestatic livers induced low Bopta $C_{\mathrm{BC}}$, increased Bopta accumulation in hepatocytes, and Bopta hepatocyte trapping during the decay period (Fig. 2c and Table 1). 

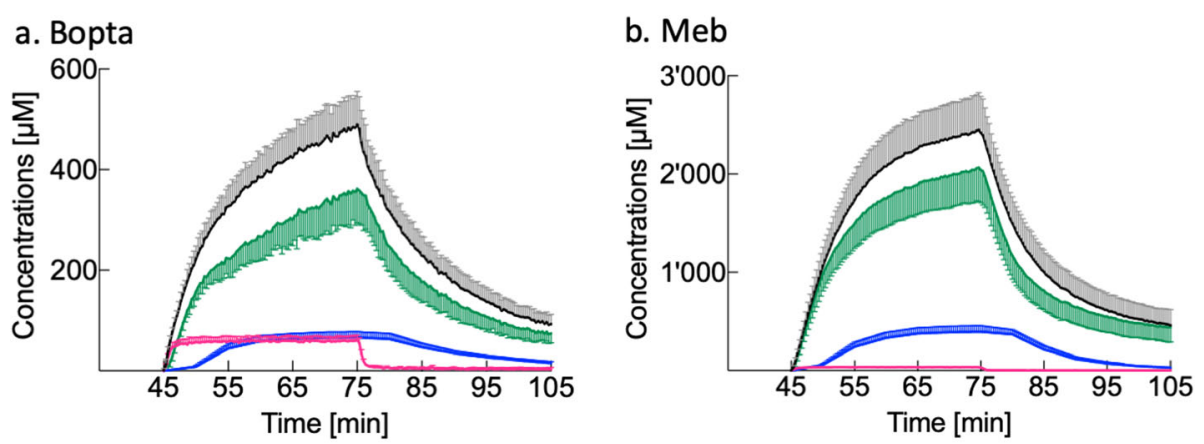

c. Bopta in rats lacking Mrp2

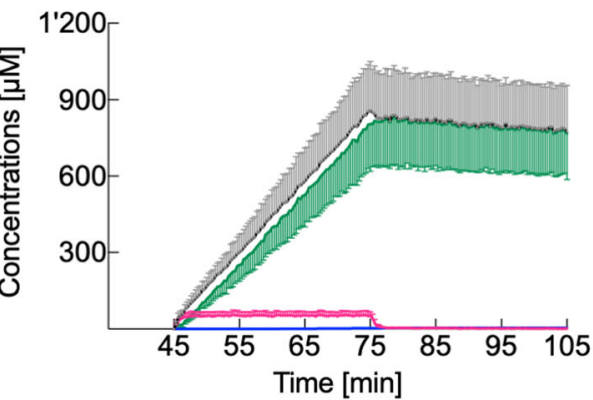

Fig. 2 Bopta and Meb compartmental distribution. a Normal livers $(n=9)$ perfused with Krebs-Henseleit bicarbonate solution (KHB) $+200 \mu$ M Bopta (45-75 min) and KHB (75-105 min). b Normal livers $(n=9)$ perfused with KHB + $64 \mu \mathrm{M} \mathrm{Meb} \mathrm{(45-75} \mathrm{min)} \mathrm{and} \mathrm{KHB} \mathrm{(75-105} \mathrm{min).} \mathrm{c} \mathrm{Cholestatic} \mathrm{livers} \mathrm{lacking} \mathrm{Mrp2} \mathrm{(} n=$ 6) perfused with KHB $+200 \mu \mathrm{M}$ Bopta (45-75 min) and KHB (75-105 min). Liver concentrations (black symbols) are measured by the counter. Concentrations in extracellular compartment (red symbols) are measured during the previous Dtpa perfusion (data not shown). Concentrations that originate from bile canaliculi (blue symbols) and from 78\% hepatocytes (green symbols) are calculated

\section{Accumulation and decay profiles of Bopta and Meb liver concentrations}

Bopta liver accumulation fitted a segmental linear regression, whilst Meb accumulation fitted a continuous hinge function (Fig. 3a, b, left panels). Both regressions were described by two lines $L_{1}$ and $L_{2}$ intersecting at $T_{0}$ or time when bile excretion started to impact the accumulation. A gentle transition between the two lines characterised Meb (Fig. 3b, left panels, red fit), whilst Bopta transition was abrupt (Fig. 3a, left panel, red fit). $T_{0}$ was slightly shorter for Meb $(5.5 \pm 1.1 \mathrm{~min})$ than Bopta $(8.0 \pm 0.5 \mathrm{~min})(p<$
0.001 , Table 2). The first lines $\left(L_{1}\right)$ below $T_{0}$ had a slope of $37 \pm 5 \mu \mathrm{M} / \mathrm{min}$ for Bopta and $333 \pm 71 \mu \mathrm{M} / \mathrm{min}$ for $\mathrm{Meb}$ $(p<0.001)$. Thus, Meb entry into livers was much higher than Bopta entry. The second lines $\left(L_{2}\right.$ for time $\left.>T_{0}\right)$ had lower slopes $(8 \pm 1 \mu \mathrm{M} / \mathrm{min}$ for Bopta and $16 \pm 5 \mu \mathrm{M} / \mathrm{min}$ for Meb, $p<0.001)$. After $T_{0}$, liver concentrations reflected the balance between uptake and excretory transporter activities. Bile concentrations were detectable 5 min after the perfusion start: 13,994 $\pm 2,391 \mu \mathrm{M}$ for Meb and $2,107 \pm 710 \mu \mathrm{M}$ for Bopta $(p<0.001)$. During the rinse period, Bopta and Meb decay of liver concentrations

Table 1 Bopta and Meb concentrations (end of accumulation period)

\begin{tabular}{lllll}
\hline Imaging agents & Bopta & Meb & , Bopta versus Meb & Bopta \\
\hline Livers & Normal & Normal & & no Mrp2 \\
$C_{\text {in }}[\mu \mathrm{M}]$ & 200 & 64 & $<00$ \\
$C_{\text {out }}[\mu \mathrm{M}]$ & $185 \pm 2$ & $5 \pm 2$ & $<001$ & $186 \pm 3^{\mathrm{ns}}$ \\
$C_{\mathrm{EC}}[\mu \mathrm{M}]$ & $60 \pm 10$ & $31 \pm 7$ & $<0.001$ & $52 \pm 16^{\mathrm{ns}}$ \\
$C_{\mathrm{BC}}[\mu \mathrm{M}]$ & $66 \pm 11$ & $393 \pm 61$ & $<0.001$ & $3 \pm 1^{* *}$ \\
$C_{\mathrm{HC78 \%}}[\mu \mathrm{M}]$ & $360 \pm 69$ & $2,043 \pm 333$ & $<0.001$ & $804 \pm 185^{* *}$ \\
$C_{\mathrm{HC100} \%}[\mu \mathrm{M}]$ & $462 \pm 88$ & $2,619 \pm 427$ & $<0.001$ & $1,031 \pm 237^{* *}$ \\
$C_{\text {bile }}[\mu \mathrm{M}]$ & $15,734 \pm 2,380$ & $94,529 \pm 9,759$ & $<0.001$ & $713 \pm 171^{* *}$ \\
\hline
\end{tabular}

Statistics between normal livers and livers lacking Mrp2 perfused with Bopta (column 2 versus column 5 ) are nonsignificant (ns) and $p<0.001$ (**). $C_{E C}$ Concentration in extracellular space, $C_{B C}$ Concentration in bile canaliculi detected by the counter, $C_{\text {bile }}$ In situ concentration in bile canaliculi and common bile duct, $C_{H C 78 \%}$ Concentration in hepatocytes detected by the counter, $C_{H C 100 \%}$ In situ hepatocyte concentrations 


\section{a. Bopta}
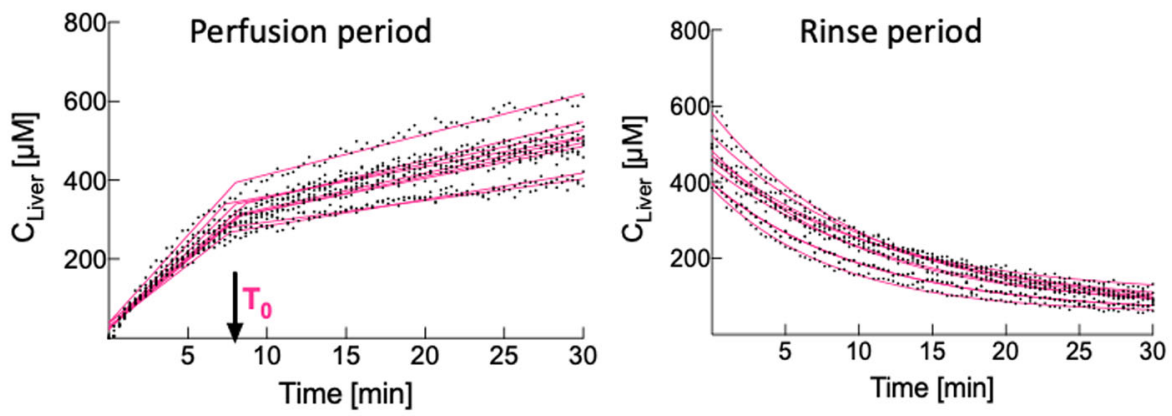

\section{b. Meb}
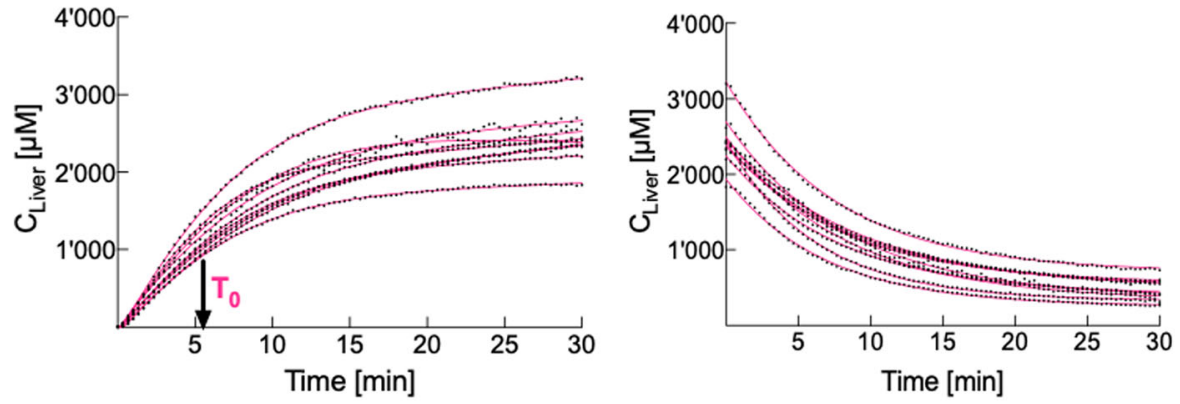

C. Bopta no Mrp2
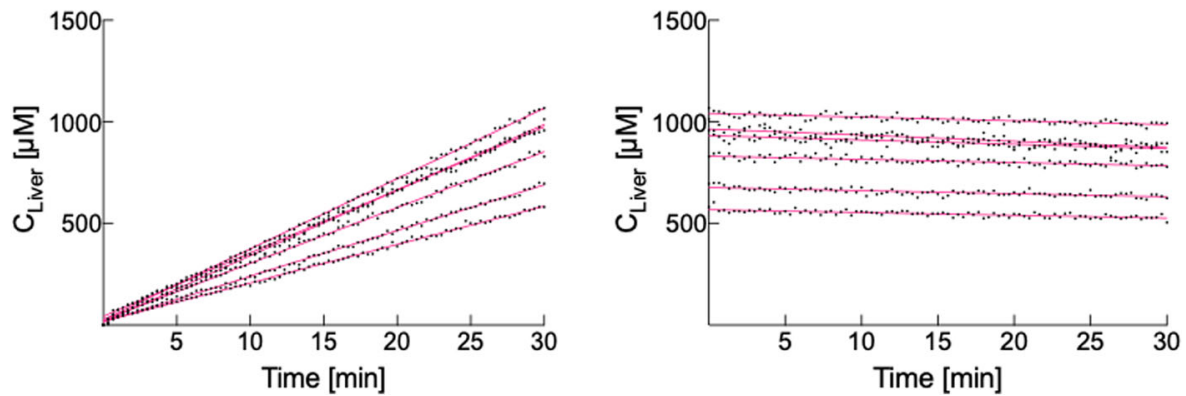

Fig. 3 Accumulation and decay of Bopta and Meb liver concentrations. a Normal livers $(n=9)$ perfused with Krebs-Henseleit bicarbonate solution $(\mathrm{KHB})+200 \mu \mathrm{M}$ Bopta (left panel) and KHB (right panel). b Normal livers $(n=9)$ perfused with KHB $+64 \mu \mathrm{M}$ Meb (left panel) and KHB (right panel). $\mathbf{c}$ Cholestatic livers lacking Mrp2 $(n=6)$ perfused with KHB +200 MM Bopta (left panel) and KHB (right panel). Bopta accumulation in normal liver (a) fitted a segmental linear regression, whilst MEB accumulation (b) fitted a continuous hinge function (gentle connections between the two lines). Both regressions are described by two lines $L_{1}$ and $L_{2}$ intersecting at $T_{0}$ or time when bile excretion started to impact the accumulation. In livers lacking Mrp2, Bopta accumulation (c) fitted a single linear regression. During the rinse period, liver concentration decay fitted a one-phase decay for Bopta and Meb (a, b, right). No Bopta decay was observed in the absence of Mrp2 (c, right)

fitted a one-phase decay (Fig. 3a, b, right panels) with a higher $k_{\mathrm{el}, \text { liver }}$ for Meb $\left(0.13 \pm 0.02 \mathrm{~min}^{-1}\right)$ than for Bopta $(0.09 \pm 0.01, p<0.001$, Table 2).

In livers lacking Mrp2, Bopta accumulation fitted a single linear regression $(L)$ during the entire perfusion period (Fig. 3c, left panel). $T_{0}$ value was not available and Bopta bile excretion was minor. The $L$ slope $(28 \pm 6$ $\mu \mathrm{M} / \mathrm{min}$ ) was significantly lower than the $L_{1}$ slope measured in normal livers $(37 \pm 5 \mu \mathrm{M} / \mathrm{min}, p=0.01)$, showing a decreased Bopta entry in cholestatic livers. There was no decay during the rinse period and Bopta remained trapped inside hepatocytes.

\section{Accumulation and decay profiles of Bopta and Meb hepatocyte concentrations}

All pharmacokinetic parameters were also measured in hepatocytes to eliminate the impact of the extracellular and canaliculi compartments on the results. In hepatocytes, both Bopta and Meb accumulation fitted a continuous hinge function during the perfusion period (data 
Table 2 Bopta and Meb accumulation and decay parameters in livers and hepatocytes

\begin{tabular}{|c|c|c|c|c|}
\hline Imaging agents & Bopta & Meb & $p$, Bopta versus Meb & Bopta \\
\hline Livers & Normal & Normal & & $\overline{\text { no Mrp2 }}$ \\
\hline$T_{0, \text { liver }}[\mathrm{min}]$ & $8.0 \pm 0.5$ & $5.5 \pm 1.1$ & $<0.001$ & - \\
\hline$T_{0, H C}[\mathrm{~min}]$ & $4.7 \pm 1.3$ & $4.0 \pm 1.5$ & .37 & - \\
\hline Slope $L_{1, \text { liver }}[\mu M / \mathrm{min}]$ & $37 \pm 5$ & $333 \pm 71$ & $<0.001$ & $28 \pm 6^{*}$ \\
\hline slope $_{1, \mathrm{HC}}[\mu \mathrm{M} / \mathrm{min}]$ & $57 \pm 16$ & $452 \pm 107$ & $<0.001$ & $35 \pm 8^{* *}$ \\
\hline Slope $L_{2, \text { liver }}[\mu M / \min ]$ & $8 \pm 1$ & $16 \pm 5$ & $<0.001$ & - \\
\hline Slope $L_{2, H C}[\mu M / m i n]$ & $8 \pm 2$ & $22 \pm 7$ & $<0.001$ & - \\
\hline$k_{\text {ell,iver }}\left[\min ^{-1}\right]$ & $0.09 \pm 0.01$ & $0.13 \pm 0.02$ & $<0.001$ & - \\
\hline$k_{\mathrm{el}, \mathrm{HC}}\left[\mathrm{min}^{-1}\right]$ & $0.10 \pm 0.02$ & $0.16 \pm 0.03$ & $<0.001$ & - \\
\hline$T_{1 / 2, \text { liver }}[\mathrm{min}]$ & $7.6 \pm 0.9$ & $5.5 \pm 0.7$ & $<0.001$ & - \\
\hline$T_{1 / 2, \mathrm{HC}}[\mathrm{min}]$ & $7.4 \pm 1.3$ & $4.5 \pm 0.6$ & $<0.001$ & - \\
\hline $\mathrm{CL}_{\mathrm{e}, \mathrm{HC}}[\mathrm{mL} / \mathrm{min}]$ & $0.95 \pm 0.17$ & $1.44 \pm 0.26$ & $<0.001$ & - \\
\hline
\end{tabular}

Bopta and Meb accumulation in normal livers and hepatocytes fitted nonlinear regressions described by two lines $L_{1}$ and $L_{2}$ intersecting at $T_{0}$ or time when bile secretion started to impact the accumulation profile. During decay, liver and hepatocyte concentrations fitted a one-phase decay described by $k_{\mathrm{el}}$ and $T_{1 / 2}$. $\mathrm{CL}_{\mathrm{el}, \mathrm{HC}}$ was calculated by $k_{\mathrm{el}} \cdot V_{\mathrm{HC}}$. Statistics between normal livers and livers lacking Mrp2 (column 2 versus column 5$)$ are $p<0.010\left({ }^{*}\right)$ and $p<0.001\left({ }^{*}\right)$. $C L_{e l, H C}$ Elimination clearance from hepatocytes, $k_{e l}$ Elimination constant rate, $H C$ Hepatocytes, $T_{1 / 2}$ Half-life of elimination, $V_{H C}$ Hepatocyte volume

not shown). $T_{0}$ were similar in both groups (Table 2). $L_{1}$ and $L_{2}$ slopes were significantly lower for Bopta than for Meb. During the decay period, the decline of hepatocyte concentrations fitted a one-phase decay with a $k_{\mathrm{el}, \mathrm{HC}}$ higher for Meb than for Bopta (Table 2). The elimination clearance from hepatocytes $\left(\mathrm{CL}_{\mathrm{el}, \mathrm{HC}}\right)$ was significantly higher for Meb than Bopta.

\section{Parameter comparisons between liver and hepatocytes}

Despite small discrepancies, liver and hepatocyte parameters were close. Bopta and Meb $T_{0, \text { liver }}$ was longer than the respective $T_{0, \mathrm{HC}}$ (Table 2). Bopta and Meb $L_{1, \text { liver }}$ slopes were lower than $L_{1, \mathrm{HC}}$ slopes. $L_{2, \text { liver }}$ and $L_{2, \mathrm{HC}}$ slopes were identical for both agents. Bopta $k_{\text {el }}$ were similar in hepatocytes and livers. Meb $k_{\mathrm{el}}$ was slightly higher in hepatocytes than in livers.

\section{Effect of acquisition frequency on pharmacokinetic parameters}

To allow more easy translation to clinical imaging, we determined the lower acquisition frequency that gives pharmacokinetic parameters similar to those measured with a 20-s frequency (Fig. 4). Similar Bopta and Meb $T_{0}$ and $L_{1}$ slopes were obtained with acquisition frequencies of $20 \mathrm{~s}, 2 \mathrm{~min}$, and $5 \mathrm{~min}$. Bopta and Meb decay parameters were similar from $20 \mathrm{~s}$ to $10 \mathrm{~min}$ (data not shown).

\section{Discussion}

Our study describes how liver extraction ratios and cholestasis interfere with the compartmental distribution of hepatobiliary agents. Meb provides much higher maximal liver concentrations than Bopta, with hepatocytes contributing to $78 \%$ of liver concentrations [20]. Meb in the extracellular compartment does not contribute much to liver concentrations, whilst Bopta in the extracellular compartment participates to liver concentrations all along the accumulation period. The contribution of bile canaliculi to liver concentrations (close to $16 \%$ ) is similar for both agents. Thus, Meb liver concentrations mainly rely on hepatocytes and bile canaliculi, whereas Bopta liver concentrations also depend on the extracellular compartment. In comparison to Bopta, Meb chemical structure has a huge affinity for the sinusoidal transporter Oatp. The second hepatobiliary MR agent gadoxetic acid which is widely used in clinical liver imaging has a higher liver extraction ratio than Bopta and its liver pharmacokinetics should be intermediate between Meb and Bopta [23-25].

In livers lacking Mrp2 and perfused with Bopta, liver concentrations only rely on the hepatocyte and extracellular compartments. The low Bopta concentrations in bile canaliculi were associated with higher hepatocyte concentrations in comparison to normal livers. This increased hepatocyte accumulation does not depend on Bopta hepatocyte uptake which is decreased. Indeed, the $L$ slope during Bopta accumulation measured in livers lacking Mrp2 was lower that the $L_{1}$ slope of normal livers. This result points out that high signal enhancements are not necessarily associated with high hepatocyte uptake. During the rinse period, Bopta remained trapped inside hepatocytes. Such results were published previously in vivo when gadoxetic acid was injected in rodents lacking Mrp2 [26].

Besides Bopta and Meb compartmental distribution, the model identifies several pharmacokinetic parameters obtained by analysing the accumulation of liver or hepatocyte concentrations. During accumulation, the time when agent excretion (in bile canaliculi or back to 

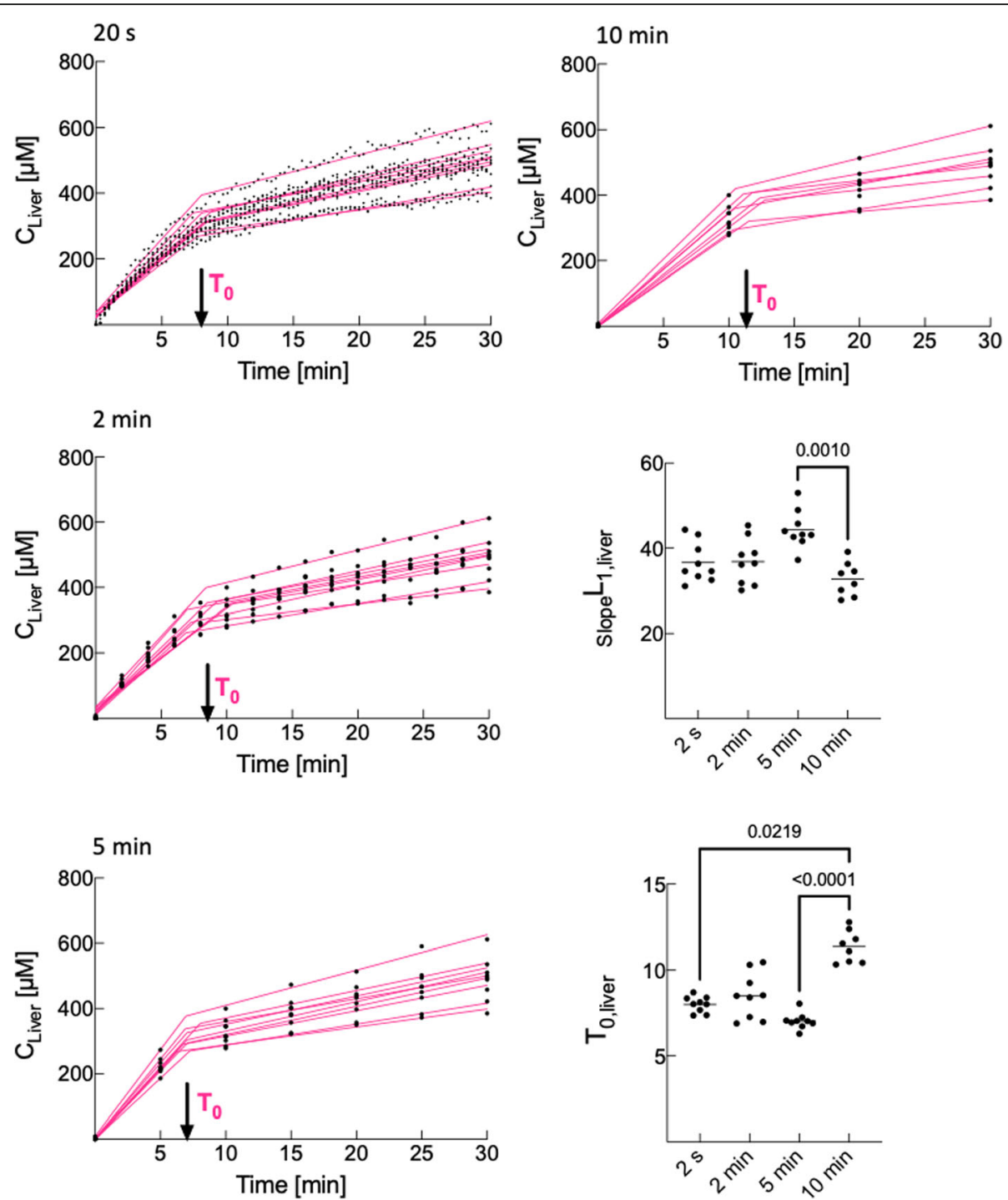

Fig. 4 Effect of acquisition frequency on pharmacokinetic parameters. We simulated lower acquisition frequencies and fitted Bopta liver concentrations with a segmental linear regression. Similar $T_{0}$ and $L_{1}$ slopes were obtained with acquisition frequency between $20 \mathrm{~s}$ and $5 \mathrm{~min}$

sinusoids) impacts hepatocytes and liver concentrations $\left(T_{0}\right)$ is important. $T_{0}$ is lower than $10 \mathrm{~min}$ and close for Bopta and Meb in normal livers. Before $T_{0}, L_{1}$ slope characterises Bopta and Meb entry (in $\mu \mathrm{M} / \mathrm{min}$ ) into hepatocytes or livers. The value is much higher for Meb than Bopta. After $T_{0}$, the accumulation rates decrease and $L_{2}$ slopes are much lower than $L_{1}$ slopes for both agents. Concomitant entry and efflux from hepatocytes or livers explain the lower $L_{2}$ slopes. Similar biphasic accumulations were previously published following bolus injection of imaging agents in patients [4, 27-29]. In these studies, slopes and $T_{0}$ were not measured by nonlinear regressions. In our study, we used two linear regressions provided by the software GraphPad Prism [21, 22]. Saito et al. [30] also showed a biphasic liver accumulation in patients with or without cirrhosis following a bolus injection of gadoxetic acid. Interestingly, the accumulation rates in the second phase (similar to our $L_{2}$ slope) decreased with the severity of cirrhosis.

In clinical practice, the hepatobiliary phase is obtained 20 min (gadoxetic acid) or later (Bopta) after injection. These time-points are superior to $T_{0}$ and are situated in the second accumulation phase when liver concentrations depend on both uptake and efflux transporters. Consequently, the clinical time-points underestimate the entry of agents into hepatocytes. Another evidence of early agent excretion from hepatocytes is provided by bile concentrations. For both agents, bile concentrations were higher than $2,000 \mu \mathrm{M} 5 \mathrm{~min}$ after the perfusion start. In clinical practice, it is not possible to acquire images every $20 \mathrm{~s}$ as done in our study. With simulations, we show that the values of $T_{0}$ and $L_{1}$ slope are similar 
until a 5-min acquisition frequency. Another important information for human imaging is that despite discrepancies, liver and hepatocyte parameters of pharmacokinetics were close.

The main pharmacokinetic parameter obtained by analysing the decay of Bopta and Meb concentrations was the elimination clearance from hepatocytes. Meb $\mathrm{CL}_{\mathrm{el}, \mathrm{HC}}$ was higher than Bopta $\mathrm{CL}_{\mathrm{el}, \mathrm{HC}}$ and null in cholestatic livers. However, this parameter does not differentiate bile efflux from efflux back into sinusoids. The distinction is unimportant for Meb which is not transported by Mrp3 back into sinusoids. In contrast, Bopta can efflux back to sinusoids $[15,19]$.

The isolated and perfused rat liver is an ex vivo model that allows the mechanistic distribution of agents and tracers in liver compartments. By placing a gamma counter over livers, we can mimic imaging systems such as magnetic resonance imaging (MRI) and single-photon computed emission tomography (SPECT). We can calculate concentrations in all liver compartments. The model clearly distinguishes in situ concentrations from concentrations detected by the counter, knowing that hepatocyte membrane transporters govern in situ concentrations. Liver concentrations detected by the counter is the sum of three in situ concentrations corrected by their respective volume ratio to liver [11]. An important restriction is that a unique volume of interest is investigated that must be delineated in homogenous tissues. The model can be applied to livers with cirrhosis and steatosis $[31,32]$.

The isolated and perfused rat liver is a convenient model because the experimental conditions are well controlled and simplified. It was useful to determine Bopta and Meb compartmental distribution, an issue inaccessible in in vivo imaging. The model is frequently used to investigate the pharmacokinetics of drugs, liver concentrations being measured by collecting biopsies over time. However, this procedure deteriorates the preparation. Such deterioration is avoided by placing a gamma counter over livers. Other experimental models, such as cultured cells or 3D tissues are not appropriate because they do not preserve the liver architecture and liver perfusion flow.

In our model, livers are perfused only through the portal vein, a condition that changes the physiological dualinput liver perfusion. However, hepatic arterial flow represents only $25 \%$ of liver blood flow. Moreover, the low portal vein pressure $(10-12 \mathrm{mmHg})$ remained steady during the entire protocol. There is no recirculation of solutions which are discarded after the first pass through sinusoids. This approach is useful to measure the pharmacokinetic parameters we need such as the liver extraction ratio $\left(C_{\text {in }}-C_{\text {out }}\right) / C_{\text {in }}$. Bopta and Meb are not metabolised and the count rates we measure only include parent compounds. We perfuse steady concentrations of agents during $30 \mathrm{~min}$, whilst Meb and Bopta are injected in clinical protocols. Following Bopta injection, human plasma concentrations remain high because the liver extraction ratio is low and Bopta remains in the systemic circulation. In contrast, Meb is rapidly cleared from the systemic circulation in patients and the perfusion we used does not mimic the clinical situation.

In conclusion, our model describes how liver extraction ratios and cholestasis interfere with the compartmental distribution of hepatobiliary agents and reveals new parameters that characterise the accumulation and decay of Bopta and Meb liver concentrations.

\section{Abbreviations \\ Bopta: Gadobenate dimeglumine; $C_{\text {bile }}[\mu \mathrm{M}]$ : Concentration in bile duct and canaliculi; $C_{B C}[\mu \mathrm{M}]$ : Concentration in bile canaliculi measured by the counter; $C_{E C}[\mu \mathrm{M}]$ : Extracellular concentration; $C_{H C 100 \%}[\mu \mathrm{M}]$ : In situ hepatocyte concentration; $C_{H C 78 \%}[\mu \mathrm{M}]$ : Concentration in hepatocytes measured by the counter; $C_{\text {in }}[\mu \mathrm{M}]$ : Perfused concentration in portal vein; $\mathrm{CL}_{\mathrm{el}}[\mathrm{mL} /$ \\ min]: Elimination clearance from hepatocytes; $C_{\text {liver }}[\mu M]$ : Liver concentration; $C_{\text {out }}[\mu \mathrm{M}]$ : Concentration in hepatic veins; Dtpa: Gadopentetate dimeglumine; $k_{\text {el }}\left[\mathrm{min}^{-1}\right]$ : Decay (elimination) rate constant; KHB: Krebs-Henseleit- \\ Bicarbonate; Meb: Mebrofenin; MRI: Magnetic resonance imaging; Mrp2: Multidrug resistance associated protein 2; Mrp3: Multidrug resistance associated protein 3; Oatp: Organic anion transporting polypeptide; $Q_{\text {bile }}$ $\left[\mu \mathrm{L} / \mathrm{min} /\right.$ liver]: Bile flow rate; $Q_{H}[\mathrm{~mL} / \mathrm{min}]$ : Liver flow rate; slope $L_{1}$ : Early accumulation of liver and hepatocyte concentrations; slope $L_{2}$ : Late accumulation of liver and hepatocyte concentrations; $T_{0}$ [min]: Time when bile excretion impacts hepatocyte and liver accumulation; $V_{H C}$ $[\mathrm{mL}]$ : Hepatocyte volume}

\section{Acknowledgements}

This work was funded by the Swiss National Foundation (number 310030126030).

\section{Authors' contributions}

Conceived and designed the study (CMP, W, and PM)

Collected the data (FJ and CMP)

Contributed to data analysis and tools (FJ and PM)

Performed the analysis (FJ)

Wrote and commented the manuscript (CMP, FJ, W, and PM)

The authors read and approved the final manuscript.

\section{Authors' information}

Catherine Pastor leads the international Hepatocyte Transporter Network. Information at https://www.unige.ch/hepatocyte-transporter-network/home.

\section{Funding}

This study has received funding by the Swiss National Foundation (number 310030-126030).

Availability of data and materials

Data are presented in the main manuscript.

\section{Declarations}

Ethics approval and consent to participate

Institutional Review Board approval was obtained for the experimental study. The protocol was carried out in accordance with the Swiss Guidelines and was approved by the veterinary office in Geneva, Switzerland.

Consent for publication

Not applicable. No individual person's data. 


\section{Competing interests}

Catherine Pastor leads the international Hepatocyte Transporter Network. Information at https://www.unige.ch/hepatocyte-transporter-network/home/. The authors of this manuscript declare no relationship with any companies, whose products or services may be related to the subject matter of the article.

\section{Author details}

'Centre de recherche sur l'inflammation, Inserm, U1149, CNRS, ERL8252, Université de Paris, F-75006 Paris, France. ${ }^{2}$ Department of Radiology, University Hospital of Geneva, Rue Gabrielle-Perret-Gentil, 4, 1205 Geneva, Switzerland. ${ }^{3}$ Department of Radiology, Hôpital Beaujon, Hôpitaux Paris Nord Val de Seine (AP-HP), 92110 Clichy, France. ${ }^{4}$ Department of Psychiatry, University Hospital of Geneva, Geneva, Switzerland. ${ }^{5}$ Department of Psychiatry, Faculty of Medicine, University of Geneva, Geneva, Switzerland.

\section{Received: 4 May 2021 Accepted: 28 July 2021}

\section{Published online: 21 September 2021}

\section{References}

1. Pastor CM, Mullhaupt B, Stieger B (2014) The role of organic anion transporters in diagnosing liver diseases by magnetic resonance imaging. Drug Metab Dispos 42:675-684. https://doi.org/10.1124/dmd.113.055707

2. Kusuhara $\mathrm{H}$ (2013) Imaging in the study of membrane transporters. Clin Pharmacol Ther 94:33-36. https://doi.org/10.1038/clpt.2013.85

3. Guo Y, Chu X, Parrott NJ, et al (2018) Advancing predictions of tissue and intracellular drug concentrations using in vitro, imaging and PBPK modeling approaches. Clin Pharmacol Ther 104:865-889. https://doi.org/10.1002/ cpt.1183

4. de Graaf W, Bennink RJ, Vetelainen R, van Gulik TM (2010) Nuclear imaging techniques for the assessment of hepatic function in liver surgery and transplantation. J Nucl Med 51:742-752. https://doi.org/10.2967/jnumed.109. 069435

5. Bastati N, Beer L, Mandorfer M, et al (2020) Does the functional liver imaging score derived from Gadoxetic acid-enhanced MRI predict outcomes in chronic liver disease? Radiology 294:98-107. https://doi.org/1 $0.1148 /$ radiol.2019190734

6. Hoekstra LT, de Graaf W, Nibourg GA et al (2013) Physiological and biochemical basis of clinical liver function tests: a review Ann Surg 257:2736. https://doi.org/10.1097/SLA.0b013e31825d5d47

7. Ba-Ssalamah A, Bastati N, Wibmer A, et al (2017) Hepatic gadoxetic acid uptake as a measure of diffuse liver disease: where are we? J Magn Reson Imaging 45:646-659. https://doi.org/10.1002/jmri.25518

8. Van Beers BE, Pastor CM, Hussain HK (2012) Primovist, Eovist: what to expect? J Hepatol 57:421-429. https://doi.org/10.1016/j.jhep.2012.01.031

9. Vilgrain $\mathrm{V}$, Van Beers BE, Pastor CM (2016) Insights into the diagnosis of hepatocellular carcinomas with hepatobiliary MRI. J Hepatol 64:708-716. https://doi.org/10.1016/j.jhep.2015.11.016

10. Vander Borght S, Libbrecht L, Blokzijl H, et al (2005) Diagnostic and pathogenetic implications of the expression of hepatic transporters in focal lesions occurring in normal liver. J Pathol 207:471-482. https://doi.org/10.1 002/path. 1852

11. Sourbron S (2014) A tracer-kinetic field theory for medical imaging. IEEE Trans Med Imaging 33:935-946. https://doi.org/10.1109/TMl.2014.2300450

12. Zhou IY, Catalano OA, Caravan P (2020) Advances in functional and molecular MRI technologies in chronic liver diseases. J Hepatol 73:12411254. https://doi.org/10.1016/j.jhep.2020.06.020

13. Poetter-Lang S, Bastati N, Messner A, et al (2020) Quantification of liver function using gadoxetic acid-enhanced MRI. Abdom Radiol (NY) 45:35323544. https://doi.org/10.1007/s00261-020-02779-x

14. Pastor CM (2018) Isolated perfused rat livers to quantify the pharmacokinetics and concentrations of Gd-BOPTA. Contrast Media Mol Imaging 2018:3839108-3839111. https://doi.org/10.1155/2018/3839108

15. Bonnaventure P, Cusin F, Pastor CM (2019) Hepatocyte concentrations of imaging compounds associated with transporter inhibition: evidence in perfused rat livers. Drug Metab Dispos 47:412-418. https://doi.org/10.1124/ dmd.118.084624

16. Millet P, Moulin M, Stieger B, Daali Y, Pastor CM (2011) How organic anions accumulate in hepatocytes lacking Mrp2: evidence in rat liver. J Pharmacol Exp Ther 336:624-632. https://doi.org/10.1124/jpet.110.175406
17. Pastor CM, Planchamp C, Pochon S, et al (2003) Kinetics of gadobenate dimeglumine in isolated perfused rat liver: MR imaging evaluation. Radiology 229:119-125. https://doi.org/10.1148/radiol.2291020726

18. Cavagna FM, Maggioni F, Castelli PM et al (1997) Gadolinium chelates with weak binding to serum proteins. A new class of high-efficiency, general purpose contrast agents for magnetic resonance imaging. Invest Radiol 32: 780-796. https://doi.org/10.1097/00004424-199712000-00009

19. Ghibellini G, Leslie EM, Pollack GM, Brouwer KL (2008) Use of tc-99m mebrofenin as a clinical probe to assess altered hepatobiliary transport: integration of in vitro, pharmacokinetic modeling, and simulation studies. Pharm Res 25:1851-1860. https://doi.org/10.1007/s11095-008-9597-0

20. Blouin A, Bolender RP, Weibel ER (1977) Distribution of organelles and membranes between hepatocytes and nonhepatocytes in the rat liver parenchyma. A stereological study. J Cell Biol 72:441-455. https://doi.org/1 $0.1083 / \mathrm{jcb} .72 .2 .441$

21. Hinge function (2021) GraphPad software, La Jolla California, USA:https:// www.graphpad.com/guides/prism/latest/curve-fitting/reg_equation-hingefunction.htm?q=hinge+function

22. Segmental linear regression (2021) GraphPad software, La Jolla California, USA:https://www.graphpad.com/guides/prism/latest/curve-fitting/reg_ segmental_linear_regression.htm

23. Schmitz SA, Mühler A, Wagner S, Wolf KJ (1996) Functional hepatobiliary imaging with Gd-EOB-DTPA. A comparison of magnetic resonance imaging and 153Gd-EOB-DTPA scintigraphy in rats. Invest Radiol 31:154-160. https:// doi.org/10.1097/00004424-199603000-00006

24. Schuhmann-Giampieri G, Schmitt-Willich H, Press WR, Negishi C, Weinmann HJ, Speck U (1992) Preclinical evaluation of Gd-EOB-DTPA as a contrast agent in MR imaging of the hepatobiliary system. Radiology 183:59-64. https://doi.org/10.1148/radiology.183.1.1549695

25. Frydrychowicz A, Lubner MG, Brown JJ, et al (2012) Hepatobiliary MR imaging with gadolinium-based contrast agents. J Magn Reson Imaging 35:492-511. https://doi.org/10.1002/jmri.22833

26. Saito S, Obata A, Kashiwagi Y, Abe K, Murase K (2013) Dynamic contrastenhanced MRI of the liver in Mrp2-deficient rats using the hepatobiliary contrast agent Gd-EOB-DTPA. Invest Radiol 48:548-553. https://doi.org/10.1 097/RLI.0b013e3182856a06

27. Truhn D, Kuhl CK, Ciritsis A, Barabasch A, Kraemer NA (2019) A new model for MR evaluation of liver function with Gadoxetic acid, including both uptake and excretion. Eur Radiol 29:383-391. https://doi.org/10.1007/s0033 0-018-5500-5

28. Nilsson H, Nordell A, Vargas R, Douglas L, Jonas E, Blomqvist L (2009) Assessment of hepatic extraction fraction and input relative blood flow using dynamic hepatocyte-specific contrast-enhanced MRI. J Magn Reson Imaging 29:1323-1331. https://doi.org/10.1002/jmri.21801

29. Ronot M, Leporq B, Van Beers BE, Vilgrain V (2019) CT and MR perfusion techniques to assess diffuse liver disease. Abdom Radiol (NY). 45:3496-3506. https://doi.org/10.1007/s00261-019-02338-z

30. Saito K, Ledsam J, Sourbron S, et al (2013) Assessing liver function using dynamic Gd-EOB-DTPA-enhanced MRI with a standard 5-phase imaging protocol. J Magn Reson Imaging 37:1109-1114. https://doi.org/10.1002/ jmri.23907

31. Planchamp C, Gex-Fabry M, Becker CD, Pastor CM (2007) Model-based analysis of Gd-BOPTA-induced MR signal intensity changes in cirrhotic rat livers. Invest Radiol 42:513-521. https://doi.org/10.1097/RLI.0b013e318036b450

32. Pastor CM, Wissmeyer M, Millet $P$ (2013) Concentrations of Gd-BOPTA in cholestatic fatty rat livers: role of transport functions through membrane proteins. Contrast Media Mol Imaging 8:147-156. https://doi.org/10.1002/ cmmi.1511

\section{Publisher's Note}

Springer Nature remains neutral with regard to jurisdictional claims in published maps and institutional affiliations. 